University of Nebraska - Lincoln

DigitalCommons@University of Nebraska - Lincoln

2020

\title{
Mutual Influence? Gender, Partner Pregnancy Desires, Fertility Intentions, and Birth Outcomes in U.S. Heterosexual Couples
}

Colleen M. Ray

Sela R. Harcey

Julia McQuillan

Arthur L. Greil

Follow this and additional works at: https://digitalcommons.unl.edu/sociologyfacpub

Part of the Family, Life Course, and Society Commons, and the Social Psychology and Interaction Commons

This Article is brought to you for free and open access by the Sociology, Department of at DigitalCommons@University of Nebraska - Lincoln. It has been accepted for inclusion in Sociology Department, Faculty Publications by an authorized administrator of DigitalCommons@University of Nebraska - Lincoln. 


\title{
Mutual Influence? Gender, Partner Pregnancy Desires, Fertility Intentions, and Birth Outcomes in U.S. Heterosexual Couples
}

\author{
Colleen M. Ray, ${ }^{1}$ Sela R. Harcey, ${ }^{1}$ \\ Julia McQuillan, ${ }^{1}$ and Arthur L. Greil ${ }^{2}$
}

1 University of Nebraska-Lincoln, Lincoln, NE, USA

2 Alfred University, Alfred, NY, USA

Corresponding author: Colleen M. Ray, University of Nebraska-Lincoln, 711 Oldfather Hall, Lincoln, NE 68588, USA. Email: colleen.ray18@gmail.com

Colleen M. Ray https://orcid.org/0000-0001-6629-0790

Sela R. Harcey https://orcid.org/0000-0002-3996-3328

Arthur L. Greil https://orcid.org/0000-0002-3101-0055

\begin{abstract}
Competing hypotheses exist with regard to how men's and women's pregnancy desires and intentions are associated with births among contemporary heterosexual couples. There are compelling cultural and structural reasons to support either the hypothesis that men's desires and intentions (patriarchal) or that women's desires and intentions (matriarchal) will have more influence, or that both partner's desires and intentions will be associated with births (mutual influence). In addition, patterns of change are likely to differ for couples that have children at wave $1 \mathrm{com}$ pared to those who do not. Path analyses of the of heterosexual couples $(n=615)$ who completed both waves of the National Survey of Fertility Barriers support the matriarchal hypothesis, because among couples without children, only women's desires were associated with subsequent births. Among couples with children, men's characteristics and desires are indirectly, and women's are directly, associated with subsequent births, indicating support for the mutual influence hypothesis.
\end{abstract}

Keywords: births, couples, desires, fertility, intentions, gendered power

Published in Journal of Family Issues 2020, 22pp

DOI: 10.1177/0192513X20906540

Copyright (C) 2020 by the authors. Published by SAGE Publications. Used by permission. 


\section{Introduction}

Researchers study fertility behavior in an effort to better understand couple dynamics, make sense of aggregate fertility trends, and recommend social policies in response to those trends. Because reproductive decision-making usually occurs in a couple context, many scholars have argued that it is important to explicitly model the dyad in fertility research (Brehm \& Schneider, 2019; Miller et al., 2004; Phillipov, 2011). Few studies, however, explicitly model partner influences on fertility intentions and subsequent births (Stein et al., 2014; Stykes, 2015). One reason couple influences on fertility are not modeled as often as they might be is that few data sets contain longitudinal data on both partners' fertility intentions (Stykes, 2015). It is possible to construct a couple measure of fertility intentions using women's reports of their partners' intentions (Korenman et al., 2002), but it is hard to know whether women's reports of partners' intentions and desires are accurate. One U.S. study that used data from both partners was gathered in the 1980s (Thomson, 1997). More recent data sets with couple data use European samples (e.g., Bauer \& Kneip, 2012; Stein et al., 2014) and focus on proceptive behavior rather than on birth as the outcome variable (see Hutteman et al., 2013 for an exception).

Even though "couples" have children, there is much about the experience of having a child (or not) that differs for men and women, even in relatively egalitarian heterosexual couples. Dramatic increases in dual-earning and dual-parenting couples in recent decades suggest that intimate unions have become more egalitarian (Goldsheider et al., 2015), but other evidence suggests an "uneven and stalled" gender revolution (England, 2010). In more egalitarian couples, both partners likely influence birth outcomes (having a child or not). Another difference is obvious, yet important, to state. Women give birth and are often primarily responsible for raising children (Stein et al., 2014), therefore some couples treat childbearing as a women's sphere and give women more influence on birth outcomes (Ferree, 2010). Alternatively, it might be that families are still relatively patriarchal and that men still have more influence over birth outcomes. When a child joins a heterosexual couple egalitarian ideologies and behaviors sometimes decline in a couple, thus suggesting that for parents, women will 
have less influence on whether or not to have another child than men (Katz-Wise et al., 2010; Yavorsky et al., 2015).

In this article, we build on prior theoretical and empirical work to address how the process of heterosexual couple-level fertility decision-making occurs. Specifically, we disentangle the influence that each partner has not only on the outcome of interest, a birth between waves, but also the effect that their own fertility desires may have on their partner's fertility intentions. We accomplish this through exploring three major questions about gender and couple fertility using data on 615 couples from a nationally representative sample: (a) How do partners influence each other's fertility desires, fertility intentions, and the odds of having a child? (i.e., patriarchal, matriarchal, or mutual influence); (b) Are gender egalitarian attitudes and education levels associated with fertility desires, intentions, and birth outcomes?; and (c) Are associations among gender, gender attitudes, education, fertility desires, fertility intentions, and subsequent births different for couples with or without children?

\section{Background}

\section{Gender and Reproductive Decision-Making}

The social context of fertility in the U.S. has changed considerably in recent decades due to an increase in access to reliable birth control, delayed onset of first births, increased women's participation in the labor force, greater influence of egalitarian gender ideology, higher men's involvement in childrearing, and the increasing variability in family structures (England, 2010). Even with the many dramatic changes in gender and family patterns in the United States, births and parenting patterns are still shaped by gendered schemas and power relations (England, 2010; Ferree, 2010; Risman, 2004). Gender scholars conceptualize families as important institutions that can "produce" gender (Berk, 1985). The concept of gendered power (Thomson, 1997) draws attention to evidence of specialization by gender in heterosexual couples. Having and raising children in the United States is expensive and demanding, with few institutional supports for combining employment and caregiving (Rehel, 2013). Individuals 
and couples therefore have children (or not) in situations shaped by resources, gender attitudes, and the number of children they already have (Goldscheider et al., 2013). Increased access to reliable birth control means that fertility desires and intentions could potentially be more aligned with one another (Guttmacher Institute, 2018). Desires for children may, however, fail to turn into intentions because of the high price of parenthood (financial, time, and career) and because of a concern that conditions be "right" for having a child before embarking on parenthood (Morgan \& Hagewen, 2005). Not all individuals who desire a baby have the circumstances permitting them to intend and then actually have a baby; therefore including measures of desiring and intending can provide unique information (Mumford et al., 2016).

Having a baby or not could reflect a mutual decision or could reflect one partner, but not the other, realizing fertility desires and intentions (Brehm \& Schneider, 2019). Theory and research suggest a number of possible models of the influence of gender on fertility decision-making in heterosexual couples (Bauer \& Kneip, 2012). The "patriarchal" model holds that, because men have more decision-making influence in heterosexual relationships, men may have more influence on reproductive decision-making (Jansen \& Liefbroer, 2006). The "spheres of influence" model (also called the "matriarchal" model) posits that, because pregnancy and birth fall under women's sphere, women may have more influence on whether or not a couple has a baby (Corijn et al., 1996). An "egalitarian" model attributes equal influence to both partners (Thomson et al., 1990). The "mutual influence" or "power" model holds that the partner with the most economic resources exercises the most influence on reproductive decision-making (Corijn et al., 1996; Jansen \& Liefbroer, 2006). There has been some empirical support for all of these models (Bauer \& Kneip, 2012; Stein et al., 2014), and therefore it is important to continue to explore couple-level fertility decision-making processes in order to understand the circumstances under which each model applies.

Many contemporary heterosexual couples desire egalitarian relationships but do not achieve them (Dudgeon \& Inhorn, 2004; England, 2010; Pedulla \& Thebaud, 2015). Most women, even those who are married with children, are employed; however, very few men are full-time fathers, and few couples fully share housework, childcare, and earning responsibility (Ferree, 2010). Some research shows that 
women delay childbearing (Goldscheider et al., 2013), or change their gender role attitudes (Schober \& Scott, 2012), when there is a disconnect between their gender egalitarian ideals and the reality within their relationships.

The effect of gender equality on fertility intentions varies by parity, age, and social class (Neyer et al., 2013). There is evidence that the association between gender egalitarianism and fertility is nonlinear; couples that are fully egalitarian or fully male-dominant have higher fertility intentions than couples with partially egalitarian relationships (Miettinen et al., 2011; Torr \& Short, 2004). Furthermore, the relationship between gender egalitarianism, and fertility intentions may be positive for women and negative for men (Kaufman, 2000). It is also unclear whether, in more male-dominant couples, the decision to have a(nother) child will be his or hers; he may retain the authority to decide, or he may delegate the decision to her. The relative influence of male and female partners could also depend upon whether or not they are already parents. Heterosexual couples often become less egalitarian and engage in more stereotypical femininity or masculinity after having children (Katz-Wise et al., 2010; Risman, 2004); this may be especially true for women (Sanchez \& Thomson, 1997).

Gender egalitarian attitudes could shape fertility desires differently for men and women. Men with more gender egalitarian attitudes could have lower fertility desires and intentions because they realize that they will have greater responsibilities with a child. Women with more gender egalitarian attitudes could have higher fertility desires and intentions because they anticipate that their partner will share childraising responsibilities. Kaufman (2000), however, finds that men who are egalitarian are more likely to intend to have a child and women who are egalitarian are less likely to intend to have a child compared to their more traditional counterparts. Gender can also shape fertility attitudes and behaviors through differential partner influences on each other and other outcomes. If both partners' fertility desires and intentions are similarly associated with subsequent births, then there is implicit evidence that fertility decisions are mutual. If there are systematic patterns that men's or women's desires and intentions have more influence on having a baby or not, then there is evidence of a gendered pattern. 
The appropriateness of different models for explaining reproductive decision- making likely depends on social context. Women may have more power in the socially constructed "female-sphere" of power such as home and family, and men may have more power in the "male sphere" of employment and earning (Ferree, 2010), but the task of differentiating men's and women's spheres is not always straightforward. A classic study (Fried \& Udry, 1979) found that, in couples in which the male partner plays more of a role in the home and with the children, males have larger influences on the childbearing decisions than women.

When partners do not share fertility expectations, it can be difficult to predict who will “win.” Voas (2003) proposed that, when partners disagree about fertility expectations, couples will have the number of children closest to the number set by community norms. Research using data from the 1980s (Thomson, 1997) found that if even one partner did not want a child, the couple was substantially less likely to have a child. Thomson et al. (1990) and Schoen et al. (1999) both failed to find a gender effect when partners disagreed. Waller (1938) theorized that the partner who is willing to walk away from the relationship has the most bargaining power. There is evidence that men have more privilege than women in many spheres (e.g., earnings, leadership positions, and authority) but less evidence that men have as much influence in the home (Ferree, 2010).

Prior research provides conflicting evidence regarding the influence of men and women in couples on having a baby or not. It is possible that partner disagreement could be resolved through partners exerting influence over each other's fertility desires and intentions, even if the power lying behind that influence is "hidden" (Komter, 1989). Women have more reproductive options (e.g., legal abortion and long acting birth control) than men, and therefore could decide de facto against having a child. Yet it could be harder for women to decide to have a child if the male partner does not want one, particularly if the male partner will leave the relationship if he does not want the child. Because gender relations typically become more traditional after the birth of the first child, the gendered distribution of power may shift with increasing parity (Risman, 2004). Other research has highlighted the fertility decision-making bargaining process (Miller and Pasta, 1994; Miller et al., 2004). Bargaining processes may be tied to 
couples' reproductive decision making. Our goal is to highlight how attitudinal mechanisms shape the bargaining process more generally.

\section{Fertility Desires and Intentions}

As noted earlier, many studies of fertility intentions only focus on women's fertility intentions (Stein et al., 2014; Stykes, 2015). Many studies have found strong relationships between fertility intentions and birth outcomes for women, but there is less evidence regarding men (Morgan \& Rackin, 2010; Quesnel-Vallee \& Morgan, 2003). Rates of unintended pregnancies are usually calculated based upon women's intentions, and some pregnancies that might not be intended by women could be intended by male partners (Cha et al., 2016). Many unintended and rapid repeat pregnancies occur as a result of reproductive coercion by male partners to pressure their female partners into becoming pregnant or maintaining a pregnancy (Cha et al., 2016; Miller et al., 2010; Moore et al., 2010). Consequently, modeling fertility at the couple- level could lead to the reclassification of some births from "unintended" to "mixed" intentions, and could help explain why women's intentions are not always realized (Dudgeon \& Inhorn, 2004). These couple processes are further complicated when either or both partners may be ambivalent, simultaneously wanting and not wanting a child (Barber et al., 2011; Brehm \& Schneider, 2019). Thus, incorporating both partner's attitudes together may help account for the complexities of intentions and desires.

Only a handful of articles simultaneously examine fertility desires and intentions (Bauer \& Kneip, 2012; Hutteman et al., 2013; Rackin \& Bachrach, 2016). Fertility desires often capture a want for children, separate from temporal information, while intentions are more grounded in time and elicit information about behaviors intended to bring about the intended outcome (Speizer et al., 2013). Miller and Pasta (1994) conceptualize desire as separate from intentions in the traits-desires-intentions-behavior (TDIB) framework of fertility. We therefore separate fertility desires and intentions so that we can we investigate the strength of each separately and can determine whether fertility desires are mediated by or incorporated in fertility intentions. Fertility intentions are often measured on a continuum (e.g., definitely avoiding to definitely intending) while fertility desires are 
often measured using categories (desire or not). Women have desires that vary in intensity; therefore, fertility desires might be better measured on a continuum rather than as simply two categories (Mumford et al., 2016).

\section{The Current Study}

We explore how men's and women's fertility desires and intentions are associated with subsequent births (or no birth) between waves for couples over an approximately three-year period. We assess whether gender is associated with fertility desires, intentions, and outcomes by comparing the strength of coefficients between women and men within couples. In addition, we investigate how these patterns differ by level of egalitarian attitudes and education among couples. If women's desires and intentions have stronger associations with fertility outcomes than men's, this is evidence that fertility is gendered as a women's sphere. If both partners' desires and intentions exhibit similar associations with fertility outcomes, this is evidence of mutual influence on having a baby or not. If men's desires and intentions have stronger associations with fertility outcomes than women's, this is evidence that fertility outcomes reflect male dominance. We present a fully recursive path model to predict subsequent births between waves for U.S. heterosexual couples, comparing parents and nonparents. We use tests of equality to determine whether these paths are significantly different for those who were not or were parents in the first wave. We model direct and indirect effects of contexts, desires, and intentions on the outcome (birth or not).

\section{Data and Methods}

\section{Data}

The National Survey of Fertility Barriers is a two-wave nationally representative dataset with measures of fertility intentions, desires, and outcomes as well as information about gender ideologies and relationship context. Data were gathered through random digit dialing (RDD) methods, which yielded a sample of 4,796 women ages 25-45 
years. Wave I data were collected in 2004-2006, and follow-up interviews were completed in 2008-2010. Using Census central office codes, high minority population areas were oversampled to provide adequate subgroup representation. To correct for this oversampling, we use weights in our analysis analyses. The response rate for Wave I is about $37 \%$, which is typical for RDD samples (McCarty et al., 2006). The Wave II data had a follow-up rate of $58 \%$, with most of the attrition due to issues with contact rather than refusal. Internal review board approval was obtained. ${ }^{1}$

A subset of male partners were asked to participate, yielding 932 of male partners for Wave I. Because male respondents were not the main respondents of the study, we cannot generalize our findings beyond men in married or cohabiting relationships with women aged 25-45 years. In addition, not all male partners were asked to participate, and not all of those who were asked complied. Among the women with partners, $47 \%$ of the partners completed the partner interview. Johnson and Johnson (2009) used the female partners' data to compare the couples in which men participated to the couples in which men did not participate among the first one-third of the completed surveys. They found that the following factors were associated with higher completion rates for men: greater relationship longevity, increased age, higher education, fatherhood, men's higher fertility intentions, the woman's having a chronic health problem, and race (partners of White women were more likely to participate).

Therefore, we are careful to generalize only to men who are married or are cohabiting with women ages 25-45 years; even so, as shown elsewhere (Johnson \& Johnson, 2009) and further, this sample is relatively advantaged in terms of education. We limited the sample to couples who were together in both waves (i.e., same partner for both waves), for whom we have data in both waves, and for whom have full data on all exogenous variables. We eliminated couples who have received a surgery of some sort that would prohibit childbearing (sterilization), because it would not be meaningful to measure fertility at Wave 2 for these couples. Our analytic sample consists of 615 couples. 


\section{Measures}

Endogenous variables. There are five endogenous variables: both partners' reports of their fertility desires, both partners' reports of their fertility intentions, and the presence of a birth between waves. The outcome variable measures whether or not the couple has had a child in the three year period between waves. Women who were pregnant at the Wave I interview were excluded in order to provide clear time order. The intentions of each partner are based upon three questions asked of both partners: "Do you intend to have a baby?" Responses were yes or no; "How sure are you that you will (or will not) have a baby?" Responses were very, somewhat, not at all. By combining these sets of questions, a scale ranging from -3 to 3 was created. Fertility desires were measured by the question "Would you like to have a baby?" The response options were on a four-point scale ranging from "definitely yes" to "definitely no" with no neutral category. Higher scores indicate stronger desires.

Exogenous and control variables. Gender ideology was measured by the following: "It is much better for everyone if the man earns the main living and the woman takes care of the home and family." The response options were on a four-point (o-3) scale ranging from "strongly agree" to "strongly disagree," with no neutral category. Higher scores indicate more gender egalitarian attitudes. Age was measured by women's age in the first wave of the study (the range was 25-45 years old). Each partner's level of education was included as an indicator of couple socioeconomic status and because education is associated with fertility. Education was measured by a series of indicator variables that capture degrees earned (e.g., "Less than high school," "High school or GED [reference category]," "Some college," "Bachelors," and "More than a bachelors"). Because the "less than a high school degree" group was very small, we combined women with less than a high school degree, a high school degree, and a GED into one group. Initial parity is based on the number of children at Wave I; those with any children were collapsed into one group (parents) compared to those with no children. 


\section{Analytic Strategy}

We used path models to estimate the indirect and direct associations of traits, desires, and intentions with birth outcomes. We used multiple-group analysis to assess whether the associations are similar for couples who did and did not have children at the initial interview (Wave 1). In order to fully capture the couple dimensions of the model, we estimated whether there are correlations among the exogenous variables (e.g. traits). Each partner's desires and intentions are likely dependent to some degree on the partner's desires and intentions (Kenny et al., 2006); couple-level analyses with correlated measures accounts for the shared variance between partners. Miller and Pasta (1994) argued that desires should lead to intentions, and intentions should lead to fertility outcomes; thus, for this study, we use a recursive model with all paths pointing in one direction. The multiple-group path model allowed us to directly compare paths between the groups through the use of equality constraints. The model is fully saturated model (i.e., all possible paths are specified) and therefore has a "perfect fit". Thus, fit statistics are not informative (Keith, 2014). Models were estimated using the maximum likelihood estimator in Mplus version 7.4 (Muthén \& Muthén, 1998-2015).

\section{Results}

Table 1 shows the descriptive statistics for the sample. Over a third of the couples (34\%; $N=208$ ) had no children at Wave I. The mean age for this sample was just under 35 years, and women partners with children were slightly older on average (35.19 years) than those without children (33.48 years). As has been found in other national random samples (DiPrete \& Buchmann, 2013), more women partners in this sample have higher education than men partners. Both women and men partners without children have higher levels of education compared to those with children. Women partners have slightly egalitarian values, with a mean of 1.68 compared with a mean of 1.64 for the men partners. Almost 40\% of both men and women, however, did not indicate that they had egalitarian attitudes. Those without children had more egalitarian values than those with children. Women partners 
Table 1. Descriptive Statistics for a Sample of 615 Couples, National Survey of Fertility Barriers.

\begin{tabular}{|c|c|c|c|c|}
\hline & \multicolumn{2}{|c|}{ No Children at Wave I } & \multicolumn{2}{|c|}{ Children at Wave I } \\
\hline & Mean $/ p$ & S.D. & Mean $/ p$ & S.D. \\
\hline Age & 33.48 & 6.35 & 35.19 & 5.60 \\
\hline \multicolumn{5}{|l|}{ Her education } \\
\hline High school or less & .07 & .25 & .15 & .36 \\
\hline Some college & .16 & .37 & .30 & .46 \\
\hline Bachelor's & .33 & .47 & .29 & .45 \\
\hline \multirow[t]{2}{*}{ Bachelor's plus } & .44 & .50 & .27 & \\
\hline & .44 & & & \\
\hline \multicolumn{5}{|l|}{ His Education } \\
\hline High school or less & .15 & .36 & .23 & .42 \\
\hline Some college & .17 & .38 & .26 & .44 \\
\hline Bachelor's & .36 & .48 & .27 & .44 \\
\hline Bachelor's plus & .31 & .46 & .25 & .43 \\
\hline Her egalitarian attitudes & 2.00 & .87 & 1.52 & .95 \\
\hline His egalitarian attitudes & 1.88 & .80 & 1.53 & .85 \\
\hline Her fertility desires & 2.04 & 1.09 & 2.11 & .98 \\
\hline His fertility desires & 2.07 & 1.04 & 1.66 & 1.14 \\
\hline Her fertility intentions & .44 & 2.29 & -.01 & 2.25 \\
\hline His fertility intentions & .51 & 2.20 & -.23 & 2.30 \\
\hline Birth between waves & .31 & .46 & .31 & .46 \\
\hline Exact match fertility desires & .57 & .50 & .45 & .50 \\
\hline General match fertility desires & .80 & .40 & .68 & .47 \\
\hline Exact match fertility intentions & .49 & .50 & .40 & .49 \\
\hline General match fertility intentions & .81 & .40 & .73 & .44 \\
\hline$N$ & 208 & & 407 & \\
\hline
\end{tabular}

Note: $\mathrm{p}$ is proportion.

had higher fertility desires $(\mathrm{M}=2.09)$ compared to men partners ( $\mathrm{M}$ = 1.80). Women partners without children had lower fertility desires than women partners with children. Among men partners, those without children had higher fertility desires than those with children. Both men and women partners without children had higher fertility intentions than those with children. Slightly less than one-third of couples (31\%), among both those with and without children at the first wave, had a child between waves.

Table 1 also shows the overlap between partner's desires and intentions using two different measures. Exact agreement on desires or intentions corresponds to the same score for both partners. The general 


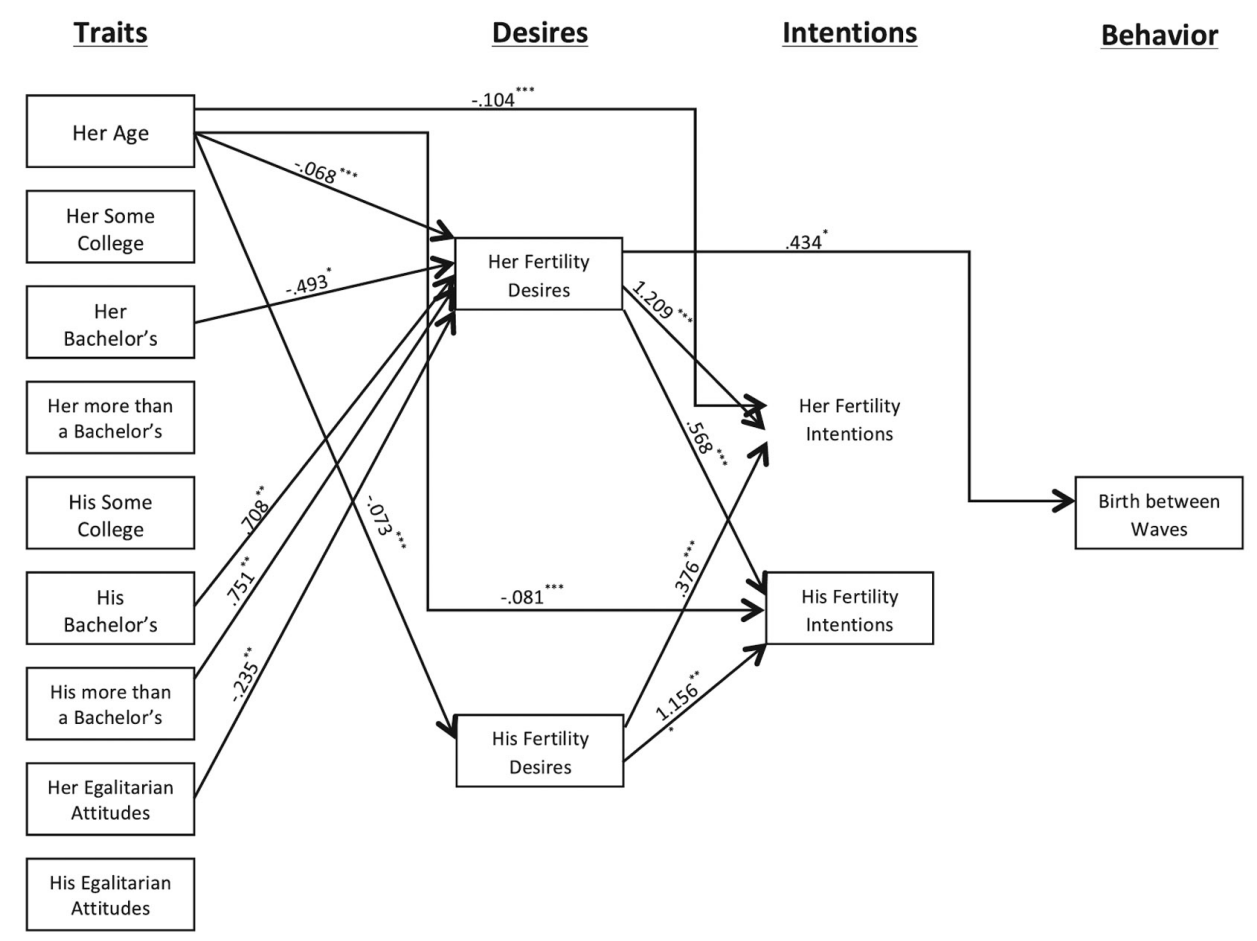

Figure 1. Significant paths for group 1 (zero parity) in model predicting birth between waves. Source: National Survey of Fertility Barriers (NSFB) Waves I and II; $\mathrm{N}=615$ heterosexual couples. Note: Figure 1 presents all significant direct paths in the model for couples without children (zero parity). Unstandardized coefficients are presented with asterisks $\left(^{*}\right)$ to denote level of significance. Wherein, ${ }^{*}=p<$ $.10,{ }^{* *}=\mathrm{p}<.05$, and $* * *=\mathrm{p}<.001$.

agreement measure combines scores at the same end of the response categories (i.e., $0-1$ and $2-3$ for desires, and $-3-1$, 0 , and 1-3 for intentions). Among those without children, men and women partners were in exact agreement on their fertility desires $57 \%$ of the time, but were in general agreement $80 \%$ of the time. For parents, however, the rates of exact ( $45 \%)$ and general (68\%) agreement on fertility intentions were lower. Similarly, among those without children, partners were in exact agreement about fertility intentions $49 \%$ of the time, but generally agreed $80 \%$ of the time. For parents, exact agreement on fertility intentions only occurred $40 \%$ of the time, and general agreement existed for $73 \%$ of couples.

Figure 1 shows the significant (unstandardized) coefficients for couples without children at Wave I. A number of traits were associated with her fertility desires. Women with higher education and older women had lower fertility desires than women with lower education 


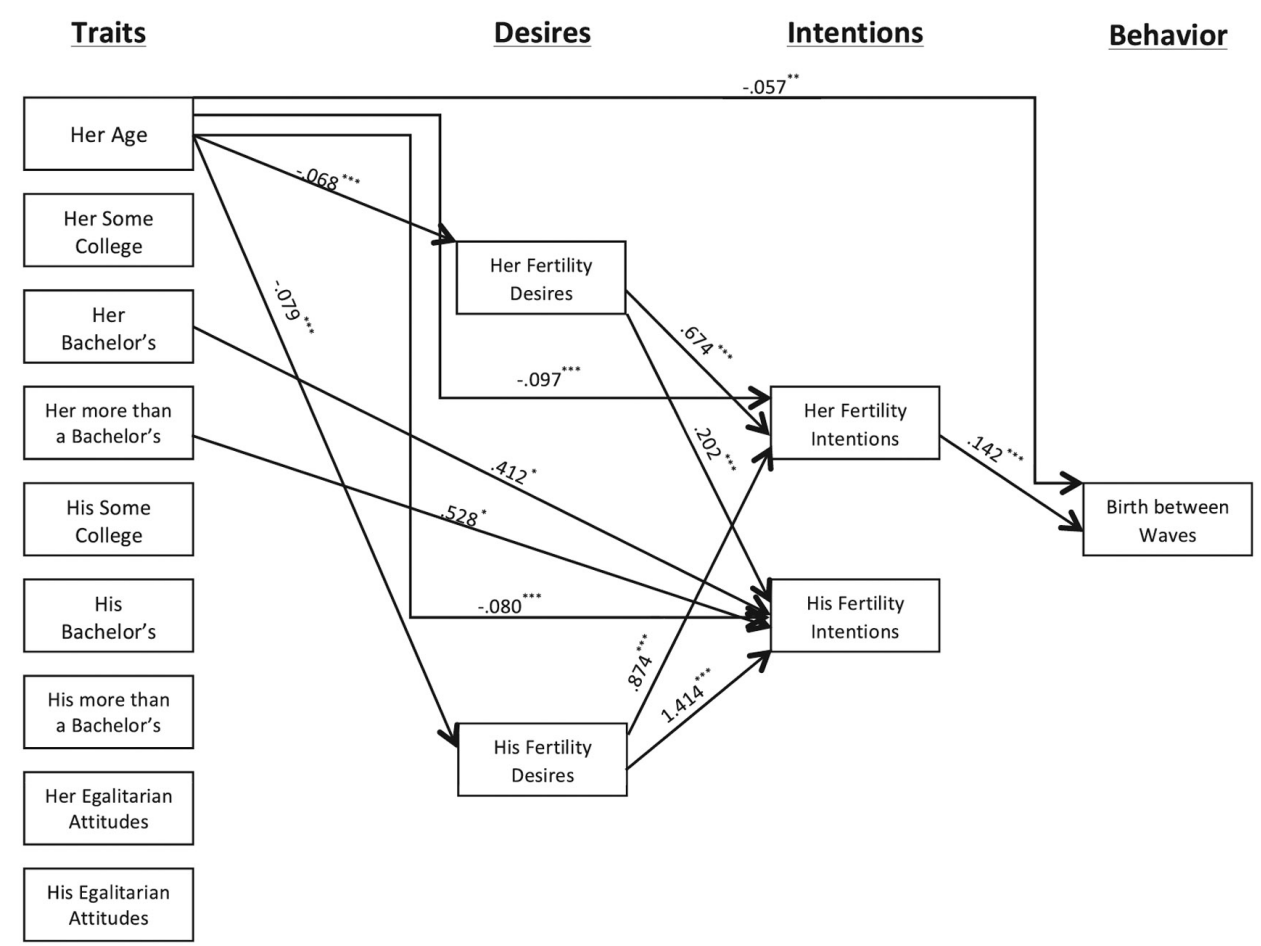

Figure 2. Significant paths for group 2 (parity 1+) in model predicting birth between waves. Source: National Survey of Fertility Barriers (NSFB) Waves I and II; $\mathrm{N}=615$ heterosexual couples. Note: Figure 2 presents all significant direct paths in the model for couples that had at least one child at Wave I (parity 1+). Unstandardized coefficients are presented with asterisks $(*)$ to denote level of significance. Wherein, ${ }^{*}=\mathrm{p}<.10,{ }^{* *}=\mathrm{p}<.05$, and ${ }^{* *}=\mathrm{p}<.001$.

or younger. In contrast, women whose partners had more education had higher fertility desires. Higher egalitarian attitudes among women were associated with lower fertility desires. The only characteristic associated with his fertility desires was partner's age; the older the female partner was, the lower the male partner's fertility desires. In the path model for couples without children at Wave I, only age had a significant indirect path through women's fertility desires to a birth between waves (results not shown). This indicates that the older a woman was, the less likely she was to desire a baby, and therefore the less likely she was to have a baby between waves.

Figure 2 shows the significant direct paths, using unstandardized coefficients, for parents (measured at Wave 1). Older age for women was associated with lower fertility desires for women and men. Similarly, higher age among women was associated with lower fertility 
Table 2a. Differences in Paths between Hers and His Desires and Intentions.

\begin{tabular}{lccc} 
Path & Women $\left(b^{F}\right)$ & Men $\left(b^{M}\right)$ & $b^{F}-b^{M}$ \\
\hline No Children at Wave I & & & \\
Desires $\rightarrow$ Her intentions & $1.209^{* * *}$ & $.376^{* * *}$ & $.834^{* * *}$ \\
Desires $\rightarrow$ His intentions & $.568^{* * *}$ & $1.156^{* * *}$ & $-.589^{* * *}$ \\
Desires $\rightarrow$ Birth outcome & $.434^{*}$ & -.123 & .557 \\
Intentions $\rightarrow$ Birth outcome & .007 & .169 & -.162 \\
Children at Wave I & & & \\
Desires $\rightarrow$ Her intentions & $.674^{* * *}$ & $.874^{* * *}$ & $-.200^{*}$ \\
Desires $\rightarrow$ His intentions & $.202^{* *}$ & $1.414^{* * *}$ & $-1.212^{* * *}$ \\
Desires $\rightarrow$ Birth outcome & .153 & .196 & -.043 \\
Intentions $\rightarrow$ Birth outcome & $.142^{* *}$ & .063 & .079 \\
\hline
\end{tabular}

"b" indicates unstandardized coefficient.

${ }^{* * *} p \leq .001 ;{ }^{* *} p \leq .01 ; * p \leq .05$.

intentions. Higher fertility desires for men and women were associated with higher fertility intentions for women; the association was stronger for men than women (Table 2). Younger women's age and higher women's education were associated with higher fertility intentions for male partners. Higher fertility desires for both men and women were associated with higher intentions for the men, but the path from his own desires to his intentions was stronger. Higher age among women was associated with lower likelihood of a birth between waves. Only higher women's fertility intentions were directly associated with a birth between waves.

There were more significant indirect paths in the model for those who were parents at Wave 1 than for those who were not parents at Wave I. Among those who were initially parents, age had an indirect association with births through her desires to her intentions, his desires to her intentions, or her intentions alone. Women's fertility desires had an indirect association through higher desires, which were associated with higher intentions and thus higher odds of having a birth between waves. Finally, men's desires were also associated with women's fertility intentions, which increase the odds of a birth between waves.

Table $2 \mathrm{a}$ shows the similarities and differences between her and his paths to intentions and birth outcome. Fertility intentions were lower among couples in which women were older. Both her fertility desires 
Table 2b. Differences in Paths between Those Without and With Children at Wave ${ }^{\dagger}$.

\begin{tabular}{llll} 
Path & No Children $\left(b^{N C}\right)$ & Children $\left(b^{c}\right)$ & $b^{N C}-b^{C}$ \\
\hline Her bachelor's $\rightarrow$ Her desire & $-.493^{*}$ & .119 & $-.612^{*}$ \\
Her more than bachelor's $\rightarrow$ Her desire & -.366 & .336 & $-.702^{*}$ \\
His bachelor's $\rightarrow$ Her desire & $.708^{* *}$ & .121 & $.587^{*}$ \\
His more than bachelor's $\rightarrow$ Her desire & $.751^{* *}$ & .139 & $.612^{*}$ \\
Her egalitarian attitudes $\rightarrow$ His desire & -.153 & .103 & $-.256^{*}$ \\
Her desire $\rightarrow$ Her intentions & $1.209^{* * *}$ & $.674^{* * *}$ & $.535^{* * *}$ \\
His desire $\rightarrow$ Her intentions & $.376^{* * *}$ & $.874^{* * *}$ & $-.498^{* * *}$ \\
Her desire $\rightarrow$ His intentions & $.568^{* * *}$ & $.202^{* *}$ & $.365^{* *}$ \\
\hline
\end{tabular}

"b" indicates unstandardized coefficient.

$* * * p \leq .001 ; * * p \leq .01 ; * p \leq .05$.

$\dagger$ Only significant path differences are shown.

and his fertility desires were positively associated with her fertility intentions; the coefficient was stronger for women than men. Both her and his fertility desires were associated with his fertility intentions; his own desires had a stronger association with his intentions. Finally, only her fertility desires were significantly associated with having a child between waves, and higher female partner fertility desires were associated with a higher likelihood of having a child between waves.

We also assessed similarities and differences between couples who initially had no children and those who initially had at least one child (Table 2b). The association of education with fertility desires was significantly different by parity; only among those without children was the association negative and significant. Similarly, men's higher education was associated with women's higher fertility desires only for couples who initially had no children. Finally, while neither path was significant, there was a significant difference in the paths between her egalitarian attitudes and his fertility desires for couples with and without children at Wave 1. When women had more egalitarian attitudes, it was associated with lower fertility desires in men among couples without children, but the opposite was true for parents. Both groups show significant and positive paths between her fertility desires and her fertility intentions, but the association was stronger for couples who initially had no children. The association of his fertility desires and her fertility intentions was stronger for parents than for nonparents. Finally, although her fertility desires were significantly and 
positively associated with his fertility intentions in both groups, this path was much stronger in couples who initially had not had children.

\section{Discussion and Conclusion}

Rather than assume that birth is a couple phenomenon, or that gender inequity is always reproduced through fertility (e.g., men dominate in heterosexual relationships, or that reproduction is women's work), we examined his and her fertility desires, intentions, and subsequent couple births (or lack of). Greater understanding of fertility desires, intentions, and births in gendered couple contexts is important for understanding gender in intimate contexts and in reducing unintended pregnancies and births, thus enhancing maternal and child health. Assuming that only women's fertility intentions and desires matter is misguided. Men matter for reproduction, and partners do not always agree on whether or not to have a child. Thomson (1997) argued that fertility decisions and outcomes are shaped by gendered power. Our goal was to estimate how much each partner influenced couple birth outcomes. In addition, we examined the direct and indirect associations of gender attitudes on birth outcomes through fertility desires and intentions, adjusted for egalitarian attitudes and education.

Our results suggest that, for couples who initially did not have children, women's desires are most strongly related to subsequently having a birth or not. Thus, the implicit assumption that reproduction is “women's sphere" seems to persist among U.S. heterosexual couples. Among those who were already parents, however, men have more influence on women's desires and intentions, consistent with studies showing more conventional gender patterns among couples with children. This differs, however, from some previous work (e.g., Bauer and Kneip, 2012) that finds that mothers have the power to make decisions about further births. Only women's intentions have a direct association with having a birth or not, but men's desires influenced women's intentions, and not the other way around. Therefore, reproduction is a couple phenomenon, not only because of the role of heterosexual sex but also because men, particularly those who are already fathers, can influence whether the couple has a baby. 
Based on Miller and Pasta's (1994) TDIB framework, we would expect that desires function through intentions to predict birth outcomes. Instead, we found that, in couples that did not already have children, fertility desires were a stronger predictor of a birth between waves than fertility intentions. For couples that already had children at Wave I, however, only fertility intentions had a direct effect on the likelihood of a birth between waves. There are several possible explanations for the lack of association between fertility intentions and a birth between waves for couples without children at Wave I. First, many people do not form definite intentions until they reach specific life course triggers for pregnancy. Second, approximately one-fourth of women are "okay either way” about pregnancy (McQuillan, Greil and Shreffler, 2011). Third, the lack of association between intentions and births may stem from a certain degree of ambivalence or uncertainty about the timing of births. These factors suggest that many women are motivated more by general fertility desires than by deliberative fertility intentions. Fourth, the sample is restricted to those ages 25 years to 45 years, thus failing to capture younger couples' experiences. People between the ages of 20 years and 25years are more likely to realize their birth intentions than those over the age of 30 years (Dommermuth et al., 2015; Régnier-Loilier et al., 2011), and omitting them from our sample may have affected our results. Fifth, the time between waves was relatively short (three years); this might not have been enough time for intentions to be translated into birth outcomes. Finally, it may be that intentions and desires are so closely correlated that one or the other variable "washes out" of the analysis when the other is controlled for.

Comparing paths for nonparents and parents revealed that men have more influence within couples who are already parents. It was striking that, for parents, the fertility desires of the male partner had a much stronger influence on both her and his own intentions, compared to the influence of her desires. This suggests that, for parents in heterosexual couples, the male partner may have more of a say in the formation of intentions for both partners. While his fertility desires shaped both her and his intentions, only the female partner's fertility intentions are associated with subsequent births. Although there was a significant association between the fertility intentions of the female partner and the birth outcome, there was a significant indirect effect 
of his fertility desires on the birth outcome, and this functioned primarily through her fertility intentions. Thus, contrary to some previous research, we found that in couples that are already parents at Wave I-who have more traditional gender attitudes-the male partner seems to play a larger role in the fertility decision- making process (Dudgeon \& Inhorn, 2004; Fried \& Udry, 1979). As described earlier, prior studies have found that couples become less egalitarian after the birth of the first child. Our results suggest that in couples that were parents at Wave I, men may dominate the decision to have a child through their stronger direct influence on her fertility intentions, which then indirectly influences the birth outcome.

Among nonparents, only her desires are associated with having a child or not. The results suggest that reproduction is within women's sphere of influence among couples without children. There is also some evidence here for the egalitarian model because among nonparents, each partner's desires had a stronger influence on their own intentions, but intentions were not associated with having a child or not; only her desires had an association with having a children nor not. Thus, it appears that among couples without children-who have more egalitarian gender attitudes-the decision-making process is more shared and that each partner seems to contribute to the decision to have a child.

Descriptive statistics (Table 1) revealed that couples who initially had children are less egalitarian than couples without children. This phenomenon may be partially due to the higher levels of education among couples that do not have children at Wave I. The more egalitarian nature of their relationship may have facilitated an equal process of decision-making. Other gendered dimensions of fertility include age (only women's age is associated with births), education (women's and men's level of education had opposite associations with fertility desires), and egalitarian attitudes (women's, but not men's, are associated with fertility desires).

We cannot then simply conclude that reproduction reflects his, her, or their desires and intentions because the answer depends upon initial parental status. For nonparents, reproduction is mostly hers, but to some extent theirs. For parents, men have more influence on reproduction through influencing women's fertility desires than women have through influencing their male partner's fertility desires. Yet 
in all of the models, there is evidence that reproduction is women's sphere, at least to certain extent, because either her desires (among nonparents) or her intentions (among parents) are the only direct associations with having a child or not.

As with any single study, there are limitations to our work. First, the measure of egalitarian attitudes is a single variable construct and may therefore fail to capture all aspects of egalitarian attitudes that affect fertility decision making processes within couples. Second, the variables included within the models may not account for all factors that influence differences in power related to couple decision-making. Third, although the TDIB framework guides our assumption that desires influence intentions, it is impossible to draw definitive conclusions about causal order because the measures for desires and intentions both come from Wave I data. Future work should extend research on the dynamics and processes around desires and intentions in relation to the outcomes of interest.

Additionally, future research should examine other measures of couple climate within this framework. Although our full sample size is fairly large, once the sample is partitioned by Wave I parity, the sample size of each subgroup may limit the power available for estimating each model. We limited the subgroups to two, but the decision-making process might appear different were we to employ an even more finely graded set of models. For instance, the decision to go from one child to two may involve a different process than going from three children to four. Future research should be conducted with larger samples that will allow finer distinctions based on parity. Due to the fact that our subsamples based on parity at Wave I differed significantly on a number of the variables within the models, further research should explore how parity is related to egalitarian attitudes within couples. It would be interesting to know whether couples become less gender-egalitarian as parity increases as some previous research has found (Katz-Wise et al., 2010).

Despite limitations, we were able to capture childbearing processes from a couple-level perspective and to examine how individual factors of fertility desires and intentions from each partner are associated with different birth outcomes for parents and nonparents. For parents, men's desires had more influence on the intentions of both partners than women's desires did, but ultimately women's intentions 
were the only ones that influenced the birth outcome. In nonparent couples, each partner had more of a say over their decision. These couple-level analyses suggest that having a baby or not is shaped by both partner's desires, but that women's desires have more direct influence than men's desires within heterosexual couples. In addition, men's desires matter more among couples who already have children than among those that do not.

\section{Declaration of conflicting interests}

The authors declared no potential conflicts of interest with respect to the research, authorship, and publication of this article.

\section{Funding}

The author(s) disclosed receipt of the following financial support for the research, authorship, and/or publication of this article: This study was supported by a grant from NICHD [Ro1-HDo44144 "Infertility: Pathways and Psychosocial Outcomes" (Lynn White and David Johnson, Co-PIs)].

\section{Note}

1. The public-access data files can be accessed at: https://www.icpsr.umich.edu/icpsrweb/ DSDR/studies/36902\#bibcite

\section{References}

Barber, J. S., Kusunoki, Y., \& Gatny, H. H. (2011). Design and implementation of an online weekly journal to study unintended pregnancies. Vienna Yearbook of Population Research/Vienna Institute of Demography, Austrian Academy of Sciences, 9, 327-334.

Bauer, G., \& Kneip, T. (2012). Fertility from a couple perspective: A test of competing decision rules on proceptive behaviour. European Sociological Review, 29(3), 535-48.

Berk, S. F. (1985). The gender factory: The apportionment of work in American households. Plenum Press.

Brehm, U., \& Schneider, N. (2019). Towards a comprehensive understanding of fertility: The model of dyadic pathways. Comparative Population Studies, 44, 3-36.

Cha, S., Chapman, D. A., Wan, W., Burton, C. W., \& Masho, S. W. (2016). Discordant pregnancy intentions in couples and rapid repeat pregnancy. American Journal of Obstetrics and Gynecology, 214(4), 494.e1-494.e11.

Corijn, M., Liefbroer, A., \& de Jong Gierveld, J. (1996). It takes two to tango, doesn't it? The influence of couple characteristics on the timing of the birth of the first child. Journal of Marriage and the Family, 58(1), 117-126. 
DiPrete, T., \& Buchmann, C. (2013). The rise of women: The growing gender gap in education and what it means for American schools. Russell Sage Foundation.

Dommermuth, L., Klobas, J., \& Lappegård, T. (2015). Realization of fertility intentions by different time frames. Advances in Life Course Research, 24, 34-46.

Dudgeon, M., \& Inhorn, M. (2004). Men's influences on women's reproductive health: Medical anthropological perspectives. Social Science \& Medicine, 59(7), 1379-1395.

England, P. (2010). The gender revolution: Uneven and stalled. Gender \& Society, 24(2), 149-166.

Ferree, M. M. (2010). Filling the glass: Gender perspectives on families. Journal of Marriage and Family, 72(3), 420-439.

Fried, E. S., \& Udry, R. (1979). Wives' and husbands' expected costs and benefits of childbearing as predictors of pregnancy. Social Biology, 26(4), 265-274.

Goldscheider, F., Bernhardt, E., \& Brandén, M. (2013). Domestic gender equality and childbearing in Sweden. Demographic Research, 29(40), 1097-1126.

Goldscheider, F., Bernhardt, E., \& Lappegård, T. (2015). The gender revolution: A framework for understanding changing family and demographic behavior. Population and Development Review, 41(2), 207-239.

Guttmacher Institute. 2018. Unintended pregnancy rates declined globally from 1990 to 2014: Larger declines in developed than developing regions. https://www.guttmacher.org/news-release/2018/ unintended-pregnancy-rates-declined-globally-1990-2014.

Hutteman, R., Bleidorn, W., Penke, L., \& Denissen, J. (2013). It takes two: A longitudinal dyadic study on predictors of fertility outcomes. Journal of Personality, 81(5), 487-498.

Jansen, M., \& Liefbroer, A. (2006). Couples' attitudes, childbirth, and the division of labor. Journal of Family Issues, 27(11), 1487-1511.

Johnson, K. M., \& Johnson, D. R. (2009). Partnered decisions? U.S. couples and medical help-seeking for infertility. Family Relations, 58(4), 431-444.

Katz-Wise, S., Priess, H., \& Hyde, J. (2010). Gender-role attitudes and behavior across the transition to parenthood. Developmental Psychology, 46(1), 18-28.

Kaufman, G. (2000). Do gender role attitudes matter? Family formation and dissolution among traditional and egalitarian men and women. Journal of Family Issues, 21(1), 128-144.

Keith, T. (2014). Multiple regression and beyond: An introduction to multiple regression and structural equation modeling. Routledge.

Kenney, D. A., Kashy, D. A., \& Cook, W. L. (2006). Dyadic data analysis. Guilford Press.

Komter, A. (1989). Hidden power in marriage. Gender \& Society, 3(2), 187-216.

Korenman, S., Kaestner, R., \& Joyce, T. (2002). Consequences for infants of parental disagreement in pregnancy intention. Perspectives on Sexual and Reproductive Health, 34(4), 198-205. 
McCarty, C., House, M., Harman, J., \& Richards, S. (2006). Effort in phone survey response rates: The effects of vendor and client-controlled factors. Field Methods, 18(2), 172-188.

McQuillan, J., Greil, A., \& Shreffler, K. (2011). Pregnancy intentions among women who do not try: Focusing on women who are okay either way. Maternal and Child Health Journal, 15(2), 178-187.

Miettinen, A., Basten, B., \& Rotkirch, A. (2011). Gender equality and fertility intentions revisited: Evidence from Finland. Demographic Research, 24, 469-496.

Miller, E., Decker, M. R., McCauley, H. L., Tancredi, D. J., Levenson, R. R., Waldman, J., Schoenwald, P., \& Silverman, J. G. (2010). Pregnancy coercion, intimate partner violence and unintended pregnancy. Contraception, 81(4), 316-322.

Miller, W., \& Pasta, D. (1994). The psychology of child timing: A measurement instrument and a model. Journal of Applied Social Psychology, 24(3), 218-250.

Miller, W., Severy, L., \& Pasta, D. (2004). A framework for modeling fertility motivation in couples. Population Studies, 58(2), 193-205.

Moore, A. M., Frohwirth, L., \& Miller, E. (2010). Male reproductive control of women who have experienced intimate partner violence in the United States. Social Science \& Medicine, 70(11), 1737-1744.

Morgan, P., \& Hagewen, K. (2005). Is very low fertility inevitable in America? Insights and forecasts from an integrative model of fertility. In A. Booth \& A. C. Crouter (Eds.), The new population problem: Why families in developed countries are shrinking and what it means (pp. 15-40). Lawrence Erlbaum.

Morgan, P., \& Rackin, H. (2010). The correspondence between fertility intentions and behavior in the United States." Population and Development Review, 36(1), 91-118.

Mumford, S., Sapra, K., King, R., Louis, J. F., \& Buck Louis, G. 2016. Pregnancy intentions: A complex construct and call for new measures. Fertility and Sterility, 106(6), 1453-1462.

Muthén, L., \& Muthén, M. (1998-2015). Mplus: Statistical analysis with latent variables: User's guide. Muthén \& Muthén.

Neyer, G., Lappegård, T. L., \& Vignoli, D. (2013). Gender equality and fertility: Which equality matters?” European Journal of Population, 29(3), 245-272.

Pedulla, D., \& Thebaud, S. (2015). Can we finish the revolution? Gender, work family ideals, and institutional constraint. American Sociological Review, 8o(1), 116-39.

Philipov, D. (2011). Theories on fertility intentions: A demographer's perspective. In S. P. Morgan, T. Sobotka, \& M. R. Testa. (Eds), Reproductive decisionmaking. Vienna yearbook of population research (pp. 37-45), Vienna: Verlag der Österreichischen Akadamie der Wissenscchaften.

Quesnel-Vallée, A., \& Morgan, P. (2003). Missing the target? Correspondence of fertility intentions and behavior in the US. Population Research and Policy Review, 22(5-6), 497-525. 
Rackin, H., \& Bachrach, C. (2016). Assessing the predictive value of fertility expectations through a cognitive-social model. Population Research and Policy Review, 35(4), 527-551.

Régnier-Loilier, A., Vignoli, D., \& Dutreuilh, C. (2011). Fertility intentions and obstacles to their realization in France and Italy. Population, 66(2), 361-389.

Rehel, E. (2013). When dad stays home too: Paternity leave, gender, and parenting. Gender \& Society, 28(1), 110-132.

Risman, B. (2004). Gender as social structure: Theory wrestling with activism. Gender \& Society, 18(4), 429-450.

Sanchez, L., \& Thomson, E. (1997). Becoming mothers and fathers: Parenthood, gender, and the division of labor. Gender \& Society, 11(6), 747-772.

Schoen, R., Astone, N. M., Kim, Y. G., Nathanson, C. J., \& Fields, J. M. (1999). Do fertility intentions affect fertility behavior? Journal of Marriage and the Family, 61(3), 790-799.

Schober, P., \& Scott, J. (2012). Maternal employment and gender role attitudes: Dissonance among British men and women in the transition to parenthood. Work, Employment, and Society, 26(3), 514-30.

Speizer, I., Calhoun, L. M., Hoke, T., \& Sengupta, R. (2013). Measurement of unmet need for family planning: Longitudinal analysis of the impact of fertility desires on subsequent childbearing behaviors among urban women from Uttar Pradesh, India. Contraception, 88(4), 553-560.

Stein, P., Willen, S., \& Pavetic, M. (2014). Couples' fertility decision-making. Demographic Research, 30, 1697-1732.

Stykes, J. B. (2015). Couples' fertility intentions: Measurement, correlates, and implications for parent and child well-being. Doctoral dissertation, Bowling Green State University, Bowling Green, OH.

Thomson, E. (1997). Couple childbearing desires, intentions, and births. Demography, 34(3), 343-354.

Thomson, E., McDonald, E., \& Bumpass, L. (1990). Fertility desires and fertility: Hers, his, and theirs. Demography, 27(4), 579-588.

Torr, B. M., \& Short, S. (2004). "Second births and the second shift: A research note on gender equity and fertility. Population and Development Review, 30(1), 109-130.

Voas, D. (2003). Conflicting preferences: A reason fertility tends to be too high or too low. Population and Development Review, 29(4), 627-646.

Waller, W. (1938). The family: A dynamic interpretation. Gordon.

Yavorsky, J., Dush, C. K., \& Schoppe-Sullivan, S. (2015). The production of inequality: The gender division of labor across the transition to parenthood. Journal of Marriage and Family, 77(3), 662-679. 